\title{
Population improvement and synthetic cultivar production in forage kale (Brassica oleracea $\mathbf{L}$.)
}

\author{
John E. Bradshaw
}

Received: 7 January 2021 / Accepted: 11 June 2021 / Published online: 26 June 2021

(C) The Author(s) 2021

\begin{abstract}
Experimental results are brought together to demonstrate that forage kale population improvement involving full-sib and selfed families can be done on an annual cycle, followed by production of a synthetic cultivar. Furthermore, this new breeding method compares favourably with the two successful methods used to date, namely triple-cross hybrid cultivars from inbreeding and crossbreeding programmes and open-pollinated cultivars from population improvement programmes. The key findings were that natural vernalization of kale in south east Scotland occurred by mid-December so that plants could be pollinated in a glasshouse with heating and lighting by the end of February and seed harvested by the end of May. The resulting full-sib or selfed families could be assessed in a field transplant trial in the same year, from June to November, thus completing an annual cycle. Self-pollination resulted in shorter plants with lower fresh-weight, dry-matter and digestible organic-matter yields, and undesirably higher contents of S-methylcysteine sulphoxide, the haemolytic anaemia factor, and the goitrogenic thiocyanate ion. As a consequence of digestible organic-matter yield being reduced by as
\end{abstract}

\section{J. E. Bradshaw}

James Hutton Institute, Invergowrie, Dundee DD2 5DA, UK

\section{J. E. Bradshaw $(\square)$}

Flat 25, 34 Simpson Loan, Edinburgh EH3 9GF, UK

e-mail: johnbradshaw949@btinternet.com much as $22 \%$, the estimated optimum number of selfed parents in a synthetic cultivar was four to eight. Synthetic cultivars are expected to yield as well as triple-cross hybrids as there was no reduction in yield when the latter were open-pollinated.

Keywords Annual breeding cycle - DOMD yield . Family selection - Inbreeding depression - Synthetic cultivar · Vernalization of kale

\section{Introduction}

Kale (Brassica oleracea $\mathrm{L}$.) reached its peak as a forage crop in Great Britain (GB) in the 1950s and 1960s, having been introduced from France during the early 1900s (Thompson 1967; Hodgkin 1995). It is still grown as a forage crop in GB and other countries with a similar climate such as New Zealand. It is mainly grazed in situ by dairy cattle in the autumn, and into the winter in the milder parts of the country. Some is grazed in situ by sheep and some is zero-grazed by forage harvester for housed stock, both beef and dairy cattle. The vegetables broccoli, Brussels sprouts, cabbage, cauliflower, Chinese kale, curled kale and kohlrabi, as well as marrow-stem and thousand-head forage kale, are all interfertile botanical varieties of B. oleracea and can be used in the breeding of forage kale. There are two key features of the reproductive biology of kale that 
are relevant to such breeding work. Firstly, kale flowers after a juvenile growth stage and vernalization (Dixon 2007). Secondly, it is an insect-pollinated outbreeding species in which self-pollination is largely prevented by a sporophytic incompatibility system (Thompson 1957). However, self-incompatible inbred lines can be produced and maintained by pollinating a bud with pollen from another flower on the same plant at least 2 days before the bud opens.

In GB most breeding work from 1951 to 1990 was government-funded and backed up by relevant research. Initially the work was done at the Plant Breeding Institute (PBI) in Cambridge (Thompson 1964, 1967) and at the Welsh Plant Breeding Station (Johnston 1963, 1964, 1965), and concentrated on inbreeding and crossbreeding programmes to produce double-cross and triple-cross hybrids. Then from 1971, work was also done at the Scottish Plant Breeding Station (SPBS) (Bradshaw and Mackay 1981, 1985; Bradshaw 1986; Bradshaw and Wilson 2012), and concentrated on population improvement programmes leading to openpollinated cultivars. The triple-cross hybrid cultivars Bittern and Maris Kestrel (Kestrel), from the PBI, and the open-pollinated cultivars Caledonian and Grampian, from the SPBS, are still being widely grown in 2021. Nevertheless, commercial companies are now interested in breeding a new generation of forage kales, but will need to rely on the pre-1990 governmentfunded research for breeding methods as virtually no new research has been done in recent years. The theory and practice of these breeding methods is covered in my book on plant breeding which contains examples from kale breeding (Bradshaw 2016).

Some previously unpublished experiments done at SPBS around 1980 may now prove useful to a new generation of breeders and are presented in this paper. They demonstrate the possibility of population improvement on an annual rather than a biennial cycle, the use of selfed $\left(S_{1}\right)$ families in the way explored through computer simulations by Bradshaw (1984), and show that a synthetic cultivar can perform as well as triple-cross hybrids. The traits considered in addition to yield are aspects of forage quality: digestible organic-matter, crude-protein, S-methylcysteine sulphoxide, the haemolytic anaemia factor which can cause kale poisoning in ruminants (Smith et al. 1974; Smith 1980), and the thiocyanate ion, a goitrogen released from the indolyl glucosinolates present in kale (Paxman and Hill 1974).

\section{Materials and methods}

Experiments were done on the vernalization requirements of kale, the production of FS (full-sib) and $S_{1}$ (selfed) families in a glasshouse and their subsequent assessment in transplant trials, the effect of selfpollination on kale cultivars, and finally the effect of open-pollination on triple-cross hybrids to provide information relevant to a consideration of synthetic cultivars. The cultural treatments in trials were typical for kale being grown in the SE of Scotland, and have been described by Bradshaw et al. (1982).

First vernalization experiment

The first experiment was done from 9 February to 3 October 1979 to determine the vernalization requirements of Maris Kestrel kale. Plants were grown in John Innes No 2 compost in $7 \mathrm{~cm}$ and then $10 \mathrm{~cm}$ square pots in a growth cabinet at $18{ }^{\circ} \mathrm{C}$ with $16 \mathrm{~h}$ light and $8 \mathrm{~h}$ dark. Two further growth cabinets were used to investigate all 24 combinations of the following vernalization treatments: $0,5,10$ and 15 true leaves on plants when transferred to vernalizing conditions (2 March, 16 March, 6 April and 4 May); 5,10 and 15 weeks of vernalization followed by return to $18{ }^{\circ} \mathrm{C}$ cabinet; and $12 \mathrm{~h}$ light at $10{ }^{\circ} \mathrm{C}$ with $12 \mathrm{~h}$ dark at either $-2{ }^{\circ} \mathrm{C}$ or $4{ }^{\circ} \mathrm{C}$. There were six plants in each combination. Plants were watered regularly and fed with liquid fertilizer from 19 July. The number of plants in each treatment combination that flowered was recorded at the end of the experiment.

\section{Second vernalization experiment}

The second experiment used natural vernalization and was briefly mentioned without detail by Bradshaw and Mackay (1981). Maris Kestrel kale had been drilled at the Murrays Farm, Pathhead, Midlothian, Scotland on 4 June 1980 and a bulk of the third generation of the 1971 population improvement programme (next section; Bradshaw and Mackay 1985) at Pentlandfield, Midlothian on 12 June 1980. Sixty plants of each (plus spare plants) were lifted and potted into $22.5 \mathrm{~cm}$ pots and stood outside a glasshouse at Pentlandfield during the last week of October. Ten plants of each were moved into the glasshouse at two-week intervals from 12 November to 21 January inclusive. The glasshouse was set to provide a minimum temperature of $13{ }^{\circ} \mathrm{C}$ 
and fluorescent tubes were used until 9 April to extend the daylength to $14 \mathrm{~h}$ with a light intensity of $8000 \mathrm{~lx}$. Once plants started to flower, they were bud-pollinated to produce selfed seed. The dates of pollination and seed harvest were recorded. Finally, the harvested seed was germinated in an incubator at $20{ }^{\circ} \mathrm{C}$ for two days and sown in rows in trays to complete the cycle.

Production and assessment of half-sib (HS), full$\mathrm{sib}(\mathrm{FS})$ and selfed $\left(\mathrm{S}_{1}\right)$ families

The material used came from the population improvement programme started at SPBS in 1971 and described in detail by Bradshaw and Mackay (1985). The initial population included Brussels sprouts, cabbages and curled kales in addition to marrow-stem and thousand-head kales, but four generations of HS family selection for digestible organic-matter yield (1971-1981) resulted in a population which consisted entirely of medium to tall marrow-stem kales. The fourth generation was produced in 1980 from the 15 HS families with the highest digestible organic-matter yields out of the 72 assessed in 1978. The winter of January to March 1979 had been very severe and none of the plants in the selection plots survived. It was therefore necessary to re-sow residual seed of the 15 families later in 1979 to raise 240 plants (15 families $\times 16$ plants) for seed production of new HS families at an isolation site in 1980. Plants were individually randomized before planting to encourage cross-pollination between plants from different families. In addition, for research purposes, 225 individually randomized plants (15 families $\times 15$ plants $)$ were kept in a glasshouse to produce FS and $S_{1}$ families by hand (bud) pollinations, which were done at the normal time of year from 7 April to 20 June.

An experiment was done in 1981 to compare some of the HS, FS and $S_{1}$ families. Thirty-two families of each type were chosen as the minimum number considered necessary for an assessment of variation. Seed constraints meant that the FS and $S_{1}$ families came from different plants. The trial site was the Murrays Farm, Pathhead, Midlothian, Scotland. The trial had a randomized complete block design with 2 replicates. The 96 families were independently randomized within each replicate from the start of the experiment, on 1 and 2 June, respectively, when the seeds in petri dishes were placed in an incubator for 2 days at $20{ }^{\circ} \mathrm{C}$ to germinate. Then 192 plots of 12 seedlings were raised in a glasshouse in Plantpaks containing a peat and sand compost. They were planted in the field on 29 June when the plants were at the 3-leaf stage. The plots were now single rows of 12 plants spaced $12.5 \mathrm{~cm}$ within rows and $50 \mathrm{~cm}$ between rows. There were guard rows along the outside rows of the trial. Plant height for each plot (canopy top as judged by eye) was measured on 26 October, after the period of rapid stem growth. The plots in the two replicates were harvested by cutting the plants at ground level on 28 October and 5 November, respectively, having removed the end plants to leave ten plants. They were weighed to determine their freshweight (FW) yield, chopped, and two representative samples taken. One was oven-dried for $18 \mathrm{~h}$ at $80{ }^{\circ} \mathrm{C}$ to determine dry-matter (DM) content and hence the dry-matter yield of each plot. The other was stored in a cold room at $-20{ }^{\circ} \mathrm{C}$ until freeze-dried for chemical analyses.

\section{Cultivar inbreeding experiment}

The aim was to determine the effect of self-pollination on the yield and quality of kale cultivars. The traditional forage kale cultivars chosen for the experiment were two dwarf winter hardy thousand-head kales (Canson and Dwarf Thousand-Head), three tall autumn marrow-stem kales (Giganta, Midas and Vulcan) and a thin-stemmed French marrow-stem kale (Proteor). Plants were raised from seed sown on 1 September 1978 and naturally vernalized over the winter in a frost-free glasshouse, having reached 11 to 12 leaves by the end of November. Appropriate hand pollinations were done in an insect-proof glasshouse from the end of April to the beginning of June 1979 with the ripe seed harvested between the middle of July and the middle of October. For each cultivar between 19 and 32 (mean 27) plants were selfpollinated and seed from each plant used to produce a bulk of selfed seed (selfs). Also, for each cultivar, between 9 and 34 (mean 17) crosses were made between pairs of plants and seed from each cross used to produce a bulk of seed from the cross-pollinations (crosses). Hence there were six bulks for the selfs and six for the crosses. In addition, bought seed of the six cultivars was available (open-pollinated), making a total of 18 bulks of seeds for sowing and assessment in 1980. 
The 1980 trial was grown in a field at Pentlandfield, Midlothian, Scotland. The trial had a randomized complete block design with three replicates, making 54 plots in total. The plots comprised five rows each of seven plants spaced $12.5 \mathrm{~cm}$ within rows and $50 \mathrm{~cm}$ between rows. The 54 lots of 35 plants were raised in a glasshouse from germinated seed ( 2 days in incubator at $20{ }^{\circ} \mathrm{C}$ ) sown on 9 June and planted in the field on 14 July. Plant height for each plot (canopy top as judged by eye) was measured on 31 October, after the period of rapid stem growth. The centre three rows of 15 plants (approximately $1 \mathrm{~m}^{2}$ ), excluding the end plants, were cut at ground level on 4 November, weighed to determine fresh-weight (FW) yield, chopped, and two representative samples taken. One was oven-dried for $18 \mathrm{~h}$ at $80^{\circ} \mathrm{C}$ to determine dry-matter (DM) content and hence the dry-matter yield of each plot. The other was stored in a cold room at $-20{ }^{\circ} \mathrm{C}$ until freeze-dried for chemical analyses. Plot yields were multiplied by 10 to convert from $\mathrm{kg} / \mathrm{plot}$ to $\mathrm{t} / \mathrm{ha}$.

Production and assessment of open-pollinated kales from triple-cross hybrids

Open-pollinated (OP) marrow-stem kales were produced in 1980 from four triple-cross hybrid cultivars: Maris Kestrel, Merlin, Condor and Peregrine. Fifty plants of each cultivar were lifted from kale plots on 27 February, in good condition as a result of the mild winter. They were planted in four separate insectproof Tygan houses for seed production. All plants were either flowering or in bud when blowflies were introduced on 4 May. Flowering had finished by 16 June and the seed harvest (ripe capsules) took place from 31 August to 19 September. Maris Kestrel and Merlin were harvested as bulks whereas individual plants of Condor and Peregrine were kept separate as OP families. Thirty plants of Condor each produced more than $15.2 \mathrm{~g}$ of seed and 30 of Peregrine each produced more than $29.8 \mathrm{~g}$, graded $1.75-2.5 \mathrm{~mm}$.

In 1981, the open-pollinated bulks of Maris Kestrel and Merlin were included in the trials of potential new cultivars which were done as described by Bradshaw et al. (1982) for the equivalent 1980 trials. Maris Kestrel and Merlin were included as standard controls. The trial sites were Yonderton, Ayr in SW Scotland; Cockle Park, Morpeth in NE England; Mylnefield, Dundee in East of Scotland; and the Murrays, Pathhead in SE Scotland. Height, fresh-weight yield, dry matter content and dry-matter yield were determined.

The OP families of Condor and Peregrine (30 each) together with Condor and Peregrine (6 plots of each) were also assessed in 1981, in a completely randomized trial of 72 plots comprising five rows, with $50 \mathrm{~cm}$ between rows and $6.25 \mathrm{~cm}$ plant spacing within rows. The trial site was the Murrays Farm, Pathhead. The trial was sown on 18 May with a precision drill, plant height measured on 14 October, and the trial was harvested on 11 and 12 November with a modified Maisprinz forage harvester which cut the plants just above ground level, chopped them, and deposited the chopped material into a box attached to a Statimeter weighing device. Fresh-weight yields were recorded from the centre three rows of each plot. Two samples of chopped kale were taken from each plot for oven and freeze drying prior to chemical analyses, as described in the previous section.

\section{Chemical analyses}

The oven-dried samples were milled through a $1 \mathrm{~mm}$ sieve in a hammer mill prior to analysis. Organicmatter (OM) content was determined by ashing in a muffle furnace. The digestible organic-matter in the dry-matter (DOMD) was determined using the cellulase method for brassicas as described by Allison and Borzucki (1978). Yield of digestible organic matter was calculated for each plot. Crude-protein (CP) content was determined by predicting the nitrogen (N) content on a fixed wavelength Technicon 'InfraAlyzer' as described by Allison et al. (1979). Each year a set of samples covering the range of predicted values was checked by the Kjeldahl method and adjustments made to the predicted values if necessary $(\mathrm{CP}=6.25$ $\times \mathrm{N}$ ). OM, DOMD and CP contents were expressed as a percentage of the DM.

The freeze-dried samples were milled through a $1 \mathrm{~mm}$ sieve in a hammer mill and then stored in plastic jars with screw-on caps in a deep freeze until they were analysed. The S-methylcysteine sulphoxide (SMCO) determinations were done using the method developed by Gosden (1979), but the chromatographic column was removed from the analytical system so that a unit of 10 columns could be used (Griffiths 1984). The thiocyanate ion $\left(\mathrm{SCN}^{-}\right)$determinations were done using the automated procedure of Gosden (1978). 
Statistical analyses

The then available version of the statistical package Genstat was used (https://www.vsni.co.uk/software/ genstat). Appropriate analyses of variance were done and the standard errors of the differences between two means (SED) of interest were estimated as $(2 \times \mathrm{MS} /$ $N)^{1 / 2}$ where MS is the mean square for the appropriate 'error' variation and $\mathrm{N}$ is the number of values contributing to each of the means being compared. When required, components of variance were estimated from the appropriate mean squares.

The data from the HS and $\mathrm{S}_{1}$ families were used to determine the optimum number of $S_{1}$ families to include in a synthetic cultivar based on the following formula (see for example: Posselt 2010; Bradshaw 2016) for the highest yielding synthetic $\left(Y_{1 \ldots \mathrm{k}}\right)$ of size $k$ out of the $n \mathrm{~S}_{1}$ families (mean $S$ ) available, where the numbering of female parents of the HS families was such that $\mathrm{gca}_{1}>\mathrm{gca}_{2}>\mathrm{gca}_{3}>\mathrm{gca}_{4}$ etc., these being the general combining abilities of the female parents [HS family mean minus mean $(C)$ of all HS families], and $S_{1 \ldots \mathrm{k}}=\left(S_{1}+S_{2}+\cdots+S_{\mathrm{k}}\right) / \mathrm{k}\left(S_{1}\right.$ is selfed family 1)

$$
\begin{aligned}
Y_{1 \ldots \mathrm{k}}= & \bar{Y}_{(\mathrm{k}-\mathrm{syn})} \\
& +\left[2(k-1) / k^{2}\right]\left(g c a_{1}+g c a_{2}+\cdots+g c a_{\mathrm{k}}\right) \\
& +(1 / k)\left(S_{1 \ldots \mathrm{k}}-S\right)
\end{aligned}
$$

where $\overline{\bar{Y}}_{(k-\text { syn })}=C-(C-S) / k$ is the mean of all $k$ parent synthetics.

As different female parents were used to produce the HS and $S_{1}$ families the formula could not be used as given. Therefore, the optimum number was estimated in two ways: firstly, assuming that $S_{1 \ldots \mathrm{k}}-$ $S$ equals zero, and secondly assuming the same ranking for the $\mathrm{HS}$ and $\mathrm{S}_{1}$ families (i.e., the best selfed family would have the best $g c a$ ). Neither of these assumptions is strictly valid, but $\left(S_{1 \ldots \mathrm{k}}-S\right) / k$ is usually small for $k>5$ and HS and $S_{1}$ families will be correlated to varying degrees dependent on the amount of non-additive genetic variation (see for example: Posselt 2010; Bradshaw 2016). The true optimum is likely to lie between these two approximations. Strictly, $Y_{1 \ldots \mathrm{k}}$ is the yield of the second generation of the synthetic cultivar derived from open-pollination of the first generation comprising all possible crosses between the $k \mathrm{~S}_{1}$ families, excluding an $\mathrm{S}_{1}$ family with itself. In the absence of epistasis, $Y_{1 \ldots \mathrm{k}}$, is also the equilibrium yield of the synthetic cultivar (Wricke and Weber 1986).

\section{Results}

First vernalization experiment

Vernalization at $-2{ }^{\circ} \mathrm{C}$ resulted in the death of from 1 to all 6 plants per treatment combination with an average of 3.42 . In contrast, vernalization at $4{ }^{\circ} \mathrm{C}$ resulted in just three losses of one plant, an average of 0.25 . Hence, only the latter results are presented in Table 1. Statistical analyses have not been done as the aim was to find conditions for all of the plants to flower. It can be seen that the actual number of true leaves at the start of vernalization differed from the target number. No plants flowered when the number of true leaves was 2 and none flowered when the vernalization period was 5 weeks. In contrast, all six plants flowered when the period was 15 weeks and the number of leaves was 10.2.

\section{Second vernalization experiment}

The results are shown in Table 2. The plants were brought into the glasshouse from 12 November to 21 January and 117 out of the 120 flowered. The pollinations were done from 15 January to 23 February (first plant flowered on 12 January) and the seed was harvested from 17 April to 5 June with 91 out of the 120 plants setting more than 10 seeds (the aim was small quantities to demonstrate success). The dates shown for pollinations and seed harvest are for the 91 plants. Seed from all 91 plants was put into an incubator to germinate on 15 June and the experiment terminated on 1 July when up to 12 seedlings from all 91 plants had two true leaves. There were only 3 plants with less than 9 seedlings.

The Maris Kestrel plants brought into the glasshouse on 11 December had from 14 to 27 leaves, including leaf scars, and their stems were 37 to $65 \mathrm{~cm}$ long. Likewise, the third-generation plants (PXS3) had from 11 to 24 leaves and their stems were $20-52 \mathrm{~cm}$ long. The pollinations and seed harvest for all of these plants were complete by 12 February and 24 May, respectively. In contrast, the plants which had been left outdoors flowered from 6 to 22 April. 
Table 1 Number of plants flowering following vernalization in $12 \mathrm{~h}$ light at $10{ }^{\circ} \mathrm{C}$ and $12 \mathrm{~h}$ dark at $4{ }^{\circ} \mathrm{C}$ for 5,10 and 15 weeks with a target of $0,5,10$ or 15 true leaves at start of vernalization (actual numbers at start and end shown)

Table 2 Dates of bringing plants into heated glasshouse, pollinations and seed harvests for 10 plants each of Maris Kestrel and bulk of the third generation of the 1971 population improvement programme (PXS3)

\begin{tabular}{llccc}
\hline Weeks & Leaves: target & Leaves at start & Leaves at end & Flowering \\
\hline 5 & 0 & 2.0 & 5.2 & $0 / 6$ \\
& 5 & 4.5 & 6.7 & $0 / 6$ \\
& 10 & 9.4 & 10.6 & $0 / 5$ \\
& 15 & 9.6 & 11.6 & $0 / 5$ \\
10 & 0 & 2.0 & 6.5 & $0 / 6$ \\
& 5 & 5.0 & 8.0 & $0 / 6$ \\
& 10 & 9.4 & 11.8 & $1 / 5$ \\
& 15 & 10.2 & 14.0 & $3 / 6$ \\
& 15 & 1.7 & 9.0 & $0 / 6$ \\
& 0 & 4.5 & 11.2 & $3 / 6$ \\
& 5 & 9.2 & 14.0 & $4 / 6$ \\
& 10 & 10.2 & 15.5 & $6 / 6$ \\
\hline
\end{tabular}

\begin{tabular}{lrll}
\hline Glasshouse & Pollinations & Seed harvest & Plants $>10$ seeds \\
\hline Maris Kestrel & & & \\
12 November & $15 / 1-2 / 2$ & $17 / 4-8 / 5$ & 7 \\
26 November & $15 / 1-2 / 2$ & $17 / 4-13 / 5$ & 9 \\
11 December & $21 / 1-2 / 2$ & $20 / 4-4 / 5$ & 10 \\
22 December & $29 / 1-4 / 2$ & $23 / 4-15 / 5$ & 10 \\
7 January & $6 / 2-12 / 2$ & $4 / 5-24 / 5$ & 9 \\
21 January & $12 / 2-12 / 2$ & $15 / 5-22 / 5$ & 5 \\
$P X S 3$ & & & 5 \\
12 November & $21 / 1-2 / 2$ & $17 / 4-13 / 5$ & 9 \\
26 November & $21 / 1-2 / 2$ & $17 / 4-19 / 5$ & 8 \\
11 December & $2 / 2-12 / 2$ & $6 / 5-24 / 5$ & 9 \\
22 December & $4 / 2-12 / 2$ & $6 / 5-22 / 5$ & 8 \\
7 January & $6 / 2-12 / 2$ & $6 / 5-29 / 5$ & 2 \\
21 January & $23 / 2-23 / 2$ & $2 / 6-5 / 6$ & \\
\hline
\end{tabular}

Production and assessment of half-sib, full-sib and selfed families

Comparisons of the means of the three types of families revealed that self-pollination resulted in shorter plants with lower yields (FW, DM and DOMD) and lower DM contents, but higher CP, SMCO and $\mathrm{SCN}^{-}$contents (Table 3). Plot yields can be multiplied by 16 to convert from $\mathrm{kg} / \mathrm{plot}$ to t/ha but could be misleading as plots were single rows of 10 plants. The means of the HS and FS families were similar for all traits.

The square roots of the genetic variances between families within type of family (32 HS, 32 FS and 32 $\mathrm{S}_{1}$ ) from the fourth generation of the 1971 population improvement programme (PXS4), and the square roots of their heritabilities (mean of two replicates), are shown in Table 4. There is evidence for genetical variation for all the traits assessed, with the most between the HS families for yield (FW, DM and DOMD), the FS families for DOMD\% and the $\mathrm{S}_{1}$ families for the other six traits. The square roots of the genetic variances could be multiplied by the square roots of their heritabilities, and the product in turn multiplied by a chosen intensity of selection to give a predicted response to family selection over generations, but this will be biased except for the HS families. Taking DOMD yield as an example, and using the results in Tables 3 and 4 for the HS families, together with the selection intensity for selecting 15 out of 150 
Table 3 Comparison of means of $32 \mathrm{HS}, 32 \mathrm{FS}$ and $32 \mathrm{~S}_{1}$ families $\left(\mathrm{S}_{1} / \mathrm{FS}\right.$ as percentage shown where statistically significant) from the fourth generation of the 1971 population improvement programme

\begin{tabular}{lccll}
\hline & HS & FS & $\mathrm{S}_{1}$ & SED \\
\hline Height cm & 87.34 & 87.73 & $83.67(95.4 \%)$ & 1.567 \\
FW yield kg/plot & 4.81 & 4.76 & $3.93(82.6 \%)$ & 0.159 \\
DM\% & 15.14 & 15.33 & $14.30(93.3 \%)$ & 0.232 \\
DM yield kg/plot & 0.728 & 0.729 & $0.561(77.0 \%)$ & 0.0250 \\
OM\% & 89.87 & 90.35 & 89.77 & 0.239 \\
DOMD\% & 77.17 & 77.76 & 77.84 & 0.596 \\
DOMD yield kg/plot & 0.561 & 0.568 & $0.437(76.9 \%)$ & 0.0197 \\
CP\% & 13.16 & 12.88 & $13.96(108.4 \%)$ & 0.222 \\
SMCO g/kg DM & 6.97 & 6.81 & $7.46(109.5 \%)$ & 0.242 \\
$\mathrm{SCN}^{-} \mathrm{mg} / 100 \mathrm{~g} \mathrm{DM}$ & 17.30 & 17.97 & $21.37(118.9 \%)$ & 1.219 \\
\hline
\end{tabular}

Table 4 Square roots of the genetic variances between families within type of family (32 HS, 32 FS and $32 \mathrm{~S}_{1}$ ) from the fourth generation of the 1971 population improvement programme, statistical significance of differences between the
32 families, and in parentheses, the square roots of the heritabilities of the differences between the 32 families ( 0 to 1 scale)

\begin{tabular}{|c|c|c|c|}
\hline & HS & FS & $\mathrm{S}_{1}$ \\
\hline Height $\mathrm{cm}$ & $4.535 * * *(0.711)$ & $3.550 * *(0.691)$ & $6.020 * * *(0.845)$ \\
\hline FW yield $\mathrm{kg} / \mathrm{plot}$ & $0.507 * * *(0.708)$ & $0.337 *(0.562)$ & $0.368 *(0.632)$ \\
\hline DM\% & $0.530 * * *(0.735)$ & $0.887 * * *(0.898)$ & $0.963 * * *(0.922)$ \\
\hline DM yield kg/plot & $0.0834 * * *(0.751)$ & $0.0497^{\mathrm{NS}}(0.527)$ & $0.0709 * * *(0.754)$ \\
\hline OM\% & $0.651 * * *(0.786)$ & $0.656 * * *(0.785)$ & $1.088 * * *(0.935)$ \\
\hline DOMD \% & $0.835^{\mathrm{NS}}(0.364)$ & $1.589 *(0.582)$ & $0.953^{\mathrm{NS}}(0.456)$ \\
\hline DOMD yield $\mathrm{kg} / \mathrm{plot}$ & $0.0682 * * *(0.795)$ & $0.0427 *(0.557)$ & $0.0537 * * *(0.728)$ \\
\hline $\mathrm{CP} \%$ & $0.459 *(0.584)$ & $0.540 *(0.637)$ & $0.733 * * *(0.725)$ \\
\hline $\mathrm{SMCO} \mathrm{g} / \mathrm{kg} \mathrm{DM}$ & $0.095^{\mathrm{NS}}(0.121)$ & $0.675 * *(0.645)$ & $0.752 * * *(0.720)$ \\
\hline $\mathrm{SCN}^{-} \mathrm{mg} / 100 \mathrm{~g} \mathrm{DM}$ & $1.888^{\mathrm{NS}}(0.502)$ & $1.556^{\mathrm{NS}}(0.424)$ & $5.726 * * *(0.866)$ \\
\hline
\end{tabular}

NS $P>0.05 ; * P 0.05-0.01 ; * * P 0.01-0.001 ; * * * P<0.001$

families (1.755 from Falconer and Mackay 1996), we have a predicted response of $0.0952 \mathrm{~kg} / \mathrm{plot}$ $(0.0682 \times 0.795 \times 1.755)$ which is a $17.0 \%$ increase on 0.561 (1.52 t/ha increase on $8.98 \mathrm{t} / \mathrm{ha})$. Selecting 6 out of 150 families would give a higher selection intensity of 2.154 and a $20.8 \%$ increase, $150 \mathrm{HS}$ families being the number actually assessed in the breeding programme in 1981 .

Highest yielding synthetic

The DOMD yield data in $\mathrm{kg} / \mathrm{plot}$ for the HS and $\mathrm{S}_{1}$ families (Table 3 ) were used to determine the optimum number of $S_{1}$ families to include in a synthetic cultivar (Table 5). It can be seen that $\bar{Y}_{(\mathrm{k}-\mathrm{syn})}$, the mean of all synthetics of size $k$, increases as $k$ increases, as expected, but the values of the other terms are such that $Y_{1 \ldots \mathrm{k}}$ reaches a maximum when $k$ is either 4 (corrected) or 6 (uncorrected), but with similar values for 3 to 7 (corrected) and 4 to 8 (uncorrected) $S_{1}$ families, respectively.

Cultivar inbreeding experiment

Analyses of variance revealed that there were no statistically significant $(P>0.05)$ interactions between the types of pollination and cultivars. Hence the differences between the types of pollination shown in Table 6 are averaged over the six cultivars. The differences are statistically significant for Height, FW, $\mathrm{DM}$ and DOMD yield, SMCO, $\mathrm{SCN}^{-}$(all $P<0.001$ ) and $\mathrm{CP} \%(P<0.05)$, but not for $\mathrm{DM} \%$, OM\% and DOMD\% (all $P>0.05$ ). Self-pollination resulted in shorter plants with lower yields (FW, DM and 
Table 5 Highest yielding (DOMD yield in kg/plot) synthetic $\left(Y_{1 \ldots \mathrm{k}}\right)$ of size $k$ where $\bar{Y}_{(\mathrm{k}-\mathrm{syn})}=C-(C-S) / k$, with $C=0.561$ and $S=0.437$ (Table 3) and $\Sigma g c a=g c a_{1}+\cdots+g c a_{\mathrm{k}}$, [(1) uncorrected and (2) corrected by $\left.+(1 / k)\left(S_{1 \ldots \mathrm{k}}-S\right)\right]$

\begin{tabular}{|c|c|c|c|c|c|c|}
\hline$k$ & $\bar{Y}_{(\mathrm{k}-\mathrm{syn})}$ & $\sum g c a$ & $\begin{array}{l}{[2(k-1) /} \\
\left.k^{2}\right] \times \Sigma g c a\end{array}$ & $Y_{1 \ldots \mathrm{k}}(1)$ & $\begin{array}{l}(1 / k)\left(S_{1 \ldots \mathrm{k}^{-}}\right. \\
S)\end{array}$ & $Y_{1 \ldots \mathrm{k}}(2)$ \\
\hline 1 & - & 0.1944 & - & - & 0.1506 & - \\
\hline 2 & 0.4990 & 0.3246 & 0.1623 & 0.6613 & 0.0750 & 0.7363 \\
\hline 3 & 0.5196 & 0.4358 & 0.1937 & 0.7133 & 0.0466 & 0.7599 \\
\hline 4 & 0.5299 & 0.5465 & 0.2049 & 0.7349 & 0.0311 & 0.7660 \\
\hline 5 & 0.5361 & 0.6392 & 0.2045 & 0.7407 & 0.0230 & 0.7637 \\
\hline 6 & 0.5403 & 0.7295 & 0.2027 & 0.7429 & 0.0180 & 0.7609 \\
\hline 7 & 0.5432 & 0.8141 & 0.1994 & 0.7426 & 0.0147 & 0.7573 \\
\hline 8 & 0.5454 & 0.8690 & 0.1901 & 0.7355 & 0.0123 & 0.7478 \\
\hline
\end{tabular}

Table 6 Type of pollination averaged over six forage kale cultivars (self/cross as percentage shown where statistically significant)

\begin{tabular}{lclll}
\hline & Open-pollination & Cross-pollination & Self-pollination & SED \\
\hline Height cm & 83.1 & 78.6 & $70.0(89.1 \%)$ & 1.81 \\
FW yield t/ha & 103.5 & 95.3 & $77.5(81.3 \%)$ & 4.17 \\
DM\% & 11.86 & 12.10 & 12.52 & 0.340 \\
DM yield t/ha & 12.24 & 11.45 & $9.67(84.5 \%)$ & 0.494 \\
OM\% & 88.24 & 88.63 & 88.54 & 0.175 \\
DOMD\% & 81.95 & 82.68 & 82.49 & 0.588 \\
DOMD yield t/ha & 10.03 & 9.45 & $7.97(84.3 \%)$ & 0.403 \\
CP\% & 19.22 & 19.01 & $20.00(105.2 \%)$ & 0.399 \\
SMCO g/kg DM & 11.46 & 11.19 & $12.44(111.2 \%)$ & 0.378 \\
SCN $^{-}$mg/100 g DM & 30.64 & 30.83 & $36.67(118.9 \%)$ & 1.420 \\
\hline
\end{tabular}

DOMD) but higher $\mathrm{CP}$, SMCO and $\mathrm{SCN}^{-}$contents. There were also statistically significant differences $(P<0.05$ or lower) between cultivars for all traits except DM\% and DOMD yield, but the results are not shown as they are not the focus of this paper.

Production and assessment of open-pollinated kales from triple-cross hybrids

The results of the assessment of the open-pollinated (OP) kales and their triple-cross hybrid parents, Maris Kestrel and Merlin, are shown in Table 7 as the means over the four sites which were treated as fixed effects. The results from individual sites are not shown as they are not the main interest of this paper. The standard errors of the differences between two means were calculated from the average error (plot to plot) variation in the four trials. They can be used for comparing Maris Kestrel with OP Maris Kestrel and
Merlin with OP Merlin. It can be seen that there are no statistically significant differences between Maris Kestrel and its open-pollinated offspring, whereas open-pollinated Merlin was taller than Merlin, with a higher DM\% and higher DM yield.

The results for the OP families of Condor and Peregrine (mean of 30 each) together with Condor and Peregrine (mean of 6 plots of each) are shown in Table 8. The standard errors of the differences between two means can be used for comparing Condor with OP Condor and Peregrine with OP Peregrine. It can be seen that there are no statistically significant differences between Condor and OP Condor and just one for Peregrine and OP Peregrine, the latter being $9 \mathrm{~cm}$ taller than the former. As there was no replication of individual OP families it is not possible to estimate the genetical variation between the families of each cultivar. 
Table 7 Means of four sites for traits assessed on open-pollinated (OP) and triple-cross hybrids Maris Kestrel (Kestrel) and Merlin

\begin{tabular}{llllll}
\hline & Kestrel & OP Kestrel & Merlin & OP Merlin & SED $^{1}$ \\
\hline Height cm & 75.84 & 78.42 & 88.25 & 99.67 & 2.888 \\
FW yield t/ha & 76.88 & 80.16 & 88.13 & 86.93 & 5.242 \\
DM\% & 14.64 & 14.22 & 13.38 & 14.34 & 0.317 \\
DM yield t/ha & 11.08 & 11.40 & 11.67 & 12.71 & 0.390 \\
\hline
\end{tabular}

${ }^{1}$ SED for comparing any two means including Kestrel with OP Kestrel and Merlin with OP Merlin

Table 8 Means of OP families of Condor and Peregrine (30 of each) together with means for Condor and Peregrine (6 plots of each)

${ }^{1} \mathrm{SED}$ for comparing Condor with OP Condor and Peregrine with OP Peregrine

\begin{tabular}{lccccc}
\hline & Condor & OP Condor & Peregrine & OP Peregrine & SED $^{1}$ \\
\hline Height cm & 88.33 & 94.83 & 88.33 & 97.33 & 3.484 \\
FW yield t/ha & 68.41 & 71.60 & 72.33 & 73.23 & 2.245 \\
DM\% & 14.74 & 14.37 & 14.46 & 14.28 & 0.398 \\
DM yield t/ha & 10.40 & 10.29 & 10.48 & 10.45 & 0.409 \\
OM\% & 90.01 & 90.10 & 90.29 & 90.32 & 0.293 \\
DOMD\% & 75.29 & 76.10 & 77.36 & 76.52 & 1.180 \\
DOMD yield t/ha & 7.82 & 7.82 & 8.10 & 8.00 & 0.308 \\
CP\% & 14.23 & 14.92 & 14.63 & 14.71 & 0.642 \\
SMCO g/kg DM $^{\text {SCN }}{ }^{-}$mg/100 g DM & 4.17 & 3.88 & 3.58 & 3.78 & 0.278 \\
\hline
\end{tabular}

\section{Discussion}

\section{Vernalization experiments}

The results of the first experiment confirmed that kale has a juvenile phase when it cannot be vernalized and that a long period of vernalization is required. Plants needed more than 10 leaves and more than 10 weeks with $12 \mathrm{~h}$ light at $10{ }^{\circ} \mathrm{C}$ and $12 \mathrm{~h}$ dark at $4{ }^{\circ} \mathrm{C}$. These results are in line with Dixon (2007) who recommended three months (13 weeks) below $10{ }^{\circ} \mathrm{C}$ for biennial brassicas like kale, with $5{ }^{\circ} \mathrm{C}$ the ideal temperature for vernalization. The second experiment demonstrated that natural vernalization can be achieved in SE Scotland by mid-December where the long-term average maximum and minimum temperatures at Edinburgh airport are as follows: October (13 and $\left.6{ }^{\circ} \mathrm{C}\right)$, November $\left(10\right.$ and $\left.3{ }^{\circ} \mathrm{C}\right)$, December $(7$ and $\left.1{ }^{\circ} \mathrm{C}\right)$, January $\left(7\right.$ and $\left.1{ }^{\circ} \mathrm{C}\right)$, February $\left(7\right.$ and $\left.1{ }^{\circ} \mathrm{C}\right)$ and March $\left(9\right.$ and $2{ }^{\circ} \mathrm{C}$ ). Adult plants brought into a glasshouse with heating and lighting on 11 December had clearly been vernalized and the pollinations and seed harvest were complete by 12 February and 24 May, respectively. There was no seed dormancy as it was possible to germinate the seed in an incubator on 15 June and to have seedlings established with two true leaves by 1 July. Hence the second experiment demonstrated that an annual breeding cycle of seed production and yield trial was just possible.

Production and assessment of half-sib (HS), fullsib (FS) and selfed $\left(\mathrm{S}_{1}\right)$ families

The fourth generation of the 1971 population improvement programme was produced in two ways in 1980. In the first way, out of the 240 plants at the isolation site, 150 produced enough seed to be assessed in 1981 as HS families in standard 5-row plots, as described by Bradshaw and Mackay (1985), for the continuation of the HS family selection programme on a biennial cycle. In the second way, FS and $S_{1}$ families were produced by hand (bud) pollinations in a glasshouse. These were done at the usual time from 7 April to 20 June, but could have been done from mid-January to the end of February, as in the second vernalization experiment, and seed harvested by the end of May. The field transplant trial could then have been done in the same year, from June to November, rather than the 
next year, and the breeding programmes simulated by Bradshaw (1984) done on an annual cycle. These simulations demonstrated that population improvement programmes involving $F S$ and $S_{1}$ families were superior to the HS family selection being practised. They considered assessment of 120 or 240 families compared with a total of 96 families in the reported transplant trial. This was thought desirable to achieve higher but realistic intensities of selection. Hence more pollinations would be required to produce more families, and larger transplant trials would be needed for their assessment, but the numbers are feasible. The other practical requirements would be an additional plot of each family to provide plants of the best families for seed production, and the need to do the chemical analyses in the short period between harvest and moving plants of the selected families to a glasshouse with heating and lighting.

The simulated schemes involving $\mathrm{FS}$ and $\mathrm{S}_{1}$ families were superior to HS family selection primarily because the order for the amount of additive genetical variation between families is $\mathrm{S}_{1}>\mathrm{FS}>\mathrm{HS}$. In the transplant trial, this order for the total amount of genetical variation was only found for four of the ten traits, $\mathrm{DM} \%, \mathrm{OM} \%, \mathrm{CP} \%$ and SMCO content (Table 4), probably because it is not possible to obtain reliable enough estimates from just 32 families assessed in two replicates of single-row plots. In a second marrow-stem kale population improvement programme started at SPBS in 1981, Bradshaw and Wilson (2012) were able to assess 88 HS and 44 FS families in a trial with two replicates and five-row plots, and to demonstrate greater genetical variation between the FS families and a greater predicted response to selection. Nevertheless, in attempting an FS or $S_{1}$ scheme on an annual cycle, it would seem desirable to follow the computer simulations (Bradshaw 1984) and produce between 120 and 240 families in order to generate adequate genetical variation on which to practise selection. The computer simulations also revealed the need to select sufficient families to avoid unnecessary random loss of desirable alleles over generations, which was slight with a minimum of 12 FS and $24 \mathrm{~S}_{1}$ families. The recommended scheme from the simulations is the one in which FS and $S_{1}$ families alternate so that the seed production is followed by the assessment trial without an intermediate round of crossing for genetic recombination without selection. However, the benefit of such a scheme is still to be demonstrated in practice.

Inbreeding and cultivar production

The final topic is cultivar production for which the effects of inbreeding and crossbreeding are relevant. The comparisons of the means of the HS, FS and $S_{1}$ families revealed that there was little difference between the HS and FS means, as expected from quantitative genetics theory, but self-pollination resulted in shorter plants with lower yields (FW, DM and DOMD) and lower DM contents, but higher CP, SMCO and $\mathrm{SCN}^{-}$contents (Table 3). Thus, the only potentially desirable change was for crude protein (CP) content. The cultivar inbreeding experiment also assessed bulks of HS, FS and $\mathrm{S}_{1}$ families and gave very similar results, with one exception. Self-pollination resulted in shorter plants with lower yields (FW, DM and DOMD) and higher $\mathrm{CP}, \mathrm{SMCO}$ and $\mathrm{SCN}^{-}$ contents, but did not result in lower DM contents and hence did not reduce DM yield and DOMD yield by so much (Table 6). Thus, comparing $S_{1} / F S$ in Table 3 with Self/Cross in Table 6 we find $82.6 \%$ and $81.3 \%$ for FW yield, $77.0 \%$ and $84.5 \%$ for DM yield, and $76.9 \%$ and $84.3 \%$ for DOMD yield. The $S_{1}$ and self-pollination means were compared with the FS and cross-pollination means, rather than with the HS and open-pollination means, because the seed was produced at the same time by bud pollinations in the same glasshouse, and not outdoors in isolation sites which might have introduced some differences. Other researchers found larger reductions on self-pollination of marrow-stem kale: Johnston (1963) reported a figure of $61.3 \%$ for FW yield which reduced to $49.6 \%$ after another cycle of self-pollination, and Watts (1970) reported a figure of $55.6 \%$ for FW yield. Watts (1970) also reported a figure of $92.0 \%$ for plant height which is similar to the $94.5 \%$ and $89.1 \%$ in Tables 3 and 6 , respectively. Hence despite differences in magnitude, it is clear that inbreeding reduces yield in kale, and it would seem reasonable to base decisions about cultivar production on the results for yield as no other trait exhibited more inbreeding depression.

It is worth looking at how the two types of successful kale cultivar have been produced. In the two SPBS programmes (Bradshaw 1986; Bradshaw and Wilson 2012) potential cultivars were produced by separately multiplying half-sib families. This 
multiplication can on average result in a reduction in yield due to inbreeding depression, equal to one quarter of that expected from one generation of selfpollination (Bradshaw 1986). For example, looking at the DOMD yield results in Table 3 for the HS and $S_{1}$ families in the fourth generation of the 1971 programme, there is a $22 \%$ reduction, a quarter of which would be $5.5 \%$. However, the half-sib families chosen for multiplication would be the superior ones in the population and the estimated superiority of the best 6 out of 150 families actually assessed in the breeding programme was a $20.8 \%$ increase. Even if this is an overestimate, the inbreeding during cultivar production does not appear to be a serious problem. In the two SPBS programmes, the potential open-pollinated cultivars had DOMD yields as good as the triple-cross hybrid cultivars from the PBI, which included Bittern and Maris Kestrel, and one became open-pollinated cultivar Grampian (Bradshaw 1986; Bradshaw and Wilson 2012).

The triple-cross hybrids are produced by the method devised by Thompson (1964), based on an understanding of self-incompatibility in B. oleracea. Six lines homozygous for different $S$ alleles are required. The production of $100 \%$ triple-cross hybrid seed by insect (bee) pollination depends on the dominance relationships between $S$ alleles in the constituent six inbred lines, as explained by Thompson (1964). Although hybrid vigour is expected, the four triple-cross hybrids were not superior in yield or other traits to their openpollinated offspring. The implication is that the same would be true of the hybrids compared with the synthetic cultivars that could be produced from their component inbred lines. This is probably because the requirements for exploiting the sporophytic incompatibility system constrained how the inbred lines were used in the production of the hybrids, and prevented the utilization of any additional heterosis that was potentially available. This makes synthetic cultivars an attractive proposition for marrow-stem kales like Maris Kestrel, Merlin, Condor and Peregrine, but not for cultivar Bittern which is a cross between marrow-stem kale and Brussels sprouts (Thompson 1967).

In this study, the optimum number of $S_{1}$ families to include in a synthetic cultivar was estimated to be four or six for DOMD yield, depending on which approximation was used for the estimate, although the predicted yields were virtually the same for four to eight parents. The best $S_{1}$ families could be used in the synthetic, but ideally HS families would be produced from the same parents of the $S_{1}$ families in order to select on their general combining abilities. Further research is required to see if this is really necessary. Becker (1988) summarized the results of a large number of experimental investigations on the optimum number of parents in a synthetic cultivar. In most experiments the optimum number of parents was 5 , and the use of more than 10 parents was never recommended. The practical question that requires further research is whether to separately maintain the parents as partially inbred lines (selfed families), as in a true synthetic cultivar, or to do further mass multiplications as in an open-pollinated cultivar.

\section{Conclusion}

The overall conclusion for a breeder starting a new forage kale programme is that population improvement schemes involving full-sib and selfed families on an annual cycle, and leading to a synthetic cultivar, are worth considering as an alternative to the two successful methods used to date, namely triple-cross hybrids from inbreeding and crossbreeding programmes and open-pollinated cultivars from population improvement programmes.

Acknowledgements Thanks are due to the farm staff and technicians who helped with the experiments, particularly Liz Young for the work on the annual breeding cycle, to the scientists in the Chemistry Department at the Scottish Crop Research Institute who supervised the chemical analyses, and to the Scottish Office Agriculture and Fisheries Department for funding.

Open Access This article is licensed under a Creative Commons Attribution 4.0 International License, which permits use, sharing, adaptation, distribution and reproduction in any medium or format, as long as you give appropriate credit to the original author(s) and the source, provide a link to the Creative Commons licence, and indicate if changes were made. The images or other third party material in this article are included in the article's Creative Commons licence, unless indicated otherwise in a credit line to the material. If material is not included in the article's Creative Commons licence and your intended use is not permitted by statutory regulation or exceeds the permitted use, you will need to obtain permission directly from the copyright holder. To view a copy of this licence, visit http://creativecommons.org/licenses/by/4.0/. 


\section{References}

Allison MJ, Borzucki R (1978) Cellulase methods for the efficient digestion of grasses and brassicas. J Sci Food Agric 29:293-297

Allison MJ, Borzucki R, Cowe IA, McHale R (1979) Scottish Plant Breeding Station Annual Report 1978-1979, pp 87-88

Becker HC (1988) Breeding synthetic varieties of crop plants. Plant Genet Breed Rev 1:31-54

Bradshaw JE (1984) Computer simulation of family selection schemes suitable for kale (Brassica oleracea L.), involving half-sib, full-sib and selfed families. Theor Appl Genet 68:503-508

Bradshaw JE (1986) The applications of biometrical genetics to the breeding of kale (Brassica oleracea L.). In: Kearsey MJ, Werner CP (eds) Proceedings of the sixth meeting of the Eucarpia section biometrics in plant breeding. EUCARPIA, Birmingham, pp 117-124

Bradshaw JE (2016) Plant breeding: past, present and future. Springer, Switzerland, p 693

Bradshaw JE, Mackay GR (1981) Kale population improvement and cultivar production. In: Gallais A (ed.) Proceedings of the fourth meeting of the Eucarpia section biometrics in plant breeding, EUCARPIA, Poitiers, pp 71-76

Bradshaw JE, Mackay GR (1985) Half-sib family selection for yield of digestible organic matter in kale (Brassica oleracea L.). Euphytica 34:201-206

Bradshaw JE, Wilson RN (2012) Kale population improvement and cultivar production. Euphytica 184:275-288

Bradshaw JE, Chapman IM, Young A (1982) Genotype-environment interactions in fodder kale (Brassica oleracea $\mathrm{L}$.). J Agric Sci, Camb 99:433-439

Dixon GR (2007) Vegetable brassicas and related crucifers. CAB International, Wallingford, p 327

Falconer DS, Mackay TFC (1996) Introduction to quantitative genetics, 4th edn. Longman, Harlow, p 464

Gosden AF (1978) An automated procedure for the estimation of thiocyanate in forage kale. J Sci Food Agric 29:597-600

Gosden AF (1979) An automated procedure for the estimation of S-methylcysteine sulphoxide in kale. J Sci Food Agric 30:892-898

Griffiths DW (1984) Report of the Scottish Crop Research Institute for 1984, pp 170

Hodgkin T (1995) Cabbages, kales, etc. In: Smartt J, Simmonds NW (eds) Evolution of crop plants, second edition. Longman Scientific \& Technical, Harlow, pp 76-82
Johnston TD (1963) Inbreeding and hybrid production in marrow-stem kale (Brassica oleracea L. var. acephala D.C.). 1. The effects of inbreeding and the performance of $F_{1}$ hybrids. Euphytica 12:198-204

Johnston TD (1964) Inbreeding and hybrid production in marrow-stem kale (Brassica oleracea L. var. acephala D.C.). 2. The Prediction of Double-Cross Performance. Euphytica 13:147-152

Johnston TD (1965) Inbreeding and hybrid production in marrow-stem kale (Brassica oleracea L. var. acephala D.C.). 3. The development and production of hybrids for commercial use. Euphytica 14:120-124

Paxman PJ, Hill R (1974) The goitrogenicity of kale and its relation to thiocyanate content. J Sci Food Agric 25:329-337

Posselt UK (2010) Breeding Methods in Cross-Pollinated Species. In: Boller B, Posselt UK, Veronesi F (eds) Fodder Crops and Amenity Grasses, Handbook of Plant Breeding 5. Springer, New York, pp 39-87

Smith RH (1980) Kale poisoning: the brassica anaemia factor. Vet Rec 107:12-15

Smith RH, Earl CR, Matheson NA (1974) The probable role of $\mathrm{S}$-methylcysteine sulphoxide in kale poisoning in ruminants. Biochem Soc Trans 2:101-104

Thompson KF (1957) Self-incompatibility in marrow-stem kale, Brassica oleracea var. acephala. I. Demonstration of a sporophytic system. J Genet 55:45-60

Thompson KF (1964) Triple-cross hybrid kale. Euphytica 13:173-177

Thompson KF (1967) Breeding problems in kale (Brassica oleracea) with particular reference to marrow-stem kale. Report of Plant Breeding Institute 1965-66:7-34

Watts LE (1970) Comparative responses of botanical varieties of Brassica oleracea L. (Brussels sprouts, sprouting broccoli and marrow stem kale) to inbreeding and hybridisation. Euphytica 19:78-90

Wricke G, Weber WE (1986) Quantitative genetics and selection in plant breeding. Walter de Gruyter, Berlin, New York, p 406

Publisher's Note Springer Nature remains neutral with regard to jurisdictional claims in published maps and institutional affiliations. 